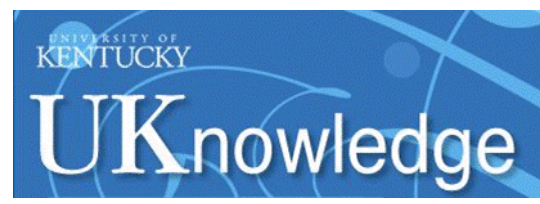

University of Kentucky

UKnowledge

$10-2018$

\title{
Measuring Knowledge and Experience in Two Mode Temporal Networks
}

\author{
Martin G. Everett \\ University of Manchester, UK \\ Chiara Broccatelli \\ University of Glasgow, UK \\ Stephen P. Borgatti \\ University of Kentucky, sborgatti@uky.edu \\ Johan Koskinen \\ University of Manchester, UK
}

Follow this and additional works at: https://uknowledge.uky.edu/management_facpub

Part of the Management Sciences and Quantitative Methods Commons

Right click to open a feedback form in a new tab to let us know how this document benefits you.

\section{Repository Citation}

Everett, Martin G.; Broccatelli, Chiara; Borgatti, Stephen P.; and Koskinen, Johan, "Measuring Knowledge and Experience in Two Mode Temporal Networks" (2018). Management Faculty Publications. 6. https://uknowledge.uky.edu/management_facpub/6

This Article is brought to you for free and open access by the Management at UKnowledge. It has been accepted for inclusion in Management Faculty Publications by an authorized administrator of UKnowledge. For more information, please contact UKnowledge@lsv.uky.edu. 


\section{Measuring Knowledge and Experience in Two Mode Temporal Networks}

\section{Digital Object Identifier (DOI)}

https://doi.org/10.1016/j.socnet.2018.05.003

\section{Notes/Citation Information}

Published in Social Networks, v. 55.

(c) 2018 Elsevier B.V.

The copyright holder has granted the permission for posting this article here.

(c) 2018. This manuscript version is made available under the CC-BY-NC-ND 4.0 license https://creativecommons.org/licenses/by-nc-nd/4.0/.

The document available for download is the authors' post-peer-review final draft of the article. 
Measuring Knowledge and Experience in Two Mode Temporal Networks

\title{
Martin G Everett*
}

The University of Manchester

\author{
Chiara Broccatelli \\ The University of Glasgow \\ Stephen P Borgatti \\ University of Kentucky \\ Johan Koskinen \\ The University of Manchester
}

*Mitchell Centre for Social Network Analysis

School of Social Sciences

University of Manchester

Arthur Lewis Building

Bridgeford Street

Manchester

M13 9PL

UK

e-mail martin.everett@manchester.ac.uk

Tel +44 (0) 1612752515 


\section{Measuring Knowledge and Experience in Two Mode Temporal Networks}

\section{Introduction}

In this paper we examine how information flows through a network as a result of interactions at events. In particular, we consider how information learnt at events is spread to other actors at subsequent events. In so doing we propose a measure that serves as an index of what an actor has gained - directly and indirectly -- from the events that they have attended. A consequence of this approach is that we only consider two mode data consisting of actors and events in which we know the order that the events occurred.

The proposed measure will be derived via a particular data representation, namely the bidynamic line-graph (BDLG), that represents individual affiliations over time as overlapping person-specific trajectories (Broccatelli, Everett and Koskinen, 2016) ${ }^{1}$. Let $V=\{\mathrm{i}, \mathrm{j}, \mathrm{k} \ldots .$.$\} be a$ set of actors and $\mathrm{E}=\{\mathrm{e} 1, \mathrm{e} 2, \ldots \mathrm{em}\}$ be a set of events which are arranged in time order, that is event ek occurs after event ej if $j<k$. Then a time stamped 2-mode network has the form G (VUE, A) where $A$ is the set of unordered pairs or edges of the form \{i,ek $\}$ in which $\mathrm{i} \square \mathrm{V}$ and ek $\square \mathrm{E}$ and indicates that actor $i$ attended event ek. This would look exactly like a standard two-mode dataset except we now have an event attribute that tells us the order in which the events took place.

Informally a BDLG representation has the edges of the time-stamped 2-mode network at its vertices and two types of edges. The first type is undirected and connects actors that were at the same event. This means that each event will be represented by a clique connecting the actorevent nodes for that event. The second type is directed and shows the trajectory of an actor through different events. Formally a BDLG representation has as its vertices the edges of G, where an edge labelled iek of the BDLG corresponds to the edge $\{\mathrm{i}, \mathrm{ek}\}$ in G. It has two types of ties, reciprocal ties and directed ties. A reciprocal tie $\{$ iex, jex $\}$ occurs when two actors $i$ and $j$ attended the same event ex. A directed tie (iex, iez) where $\mathrm{z}$ is the smallest $\mathrm{z}>\mathrm{x}$ such that $\mathrm{i}$ attended ez. The directed edge shows the next event, ez, i attended after attending event ex. Consider, for example, the BDLG shown in figure 1 representing individuals attending several events over time.

$1 \mathrm{Dr}$ Wouter Spekkink developed a tool that transforms two-mode data into BDLG. The tool can be downloaded from here: http://www.wouterspekkink.org/software/2017/03/10/bi-dynamic-line-graphs.html 
[Figure 1 about here]

To ensure a clear identification of participants in events, nodes are labelled by a number and an alphabetic letter 'e' followed by a number so that $(5, \mathrm{e} 3)$ would mean that actor 5 attended event e3. The numbers, e.g. 1,2,3..., identify individuals whereas the alphabetic letters 'e' followed by a number refer to events. If an individual participated in succeeding events, there are as many nodes involving that individual as the number of events in which the individual took part, and these nodes are sequentially connected by a directed arc. For example, the node referring to individual 2 participating at event $1(2, \mathrm{e} 1)$ has an outgoing tie only toward the node referring to individual 2 participating at event $2(2, \mathrm{e} 2)$ and from this, only an outgoing tie toward the node referring to individual 2 participating at event $4(2, \mathrm{e} 4)$. If individual 2 was also attending event 3 , another outgoing tie starting from 2,e2 and finishing in 2,e3 would be present. Therefore, each node can only have a directed tie to (from)its following (preceding) event.

In graph theory, two nodes connected by a line are said to be adjacent to one another. Since in the BDLG representation there are two different sets of ties - reciprocal and directed - the adjacency concept assumes a slightly different meaning depending upon the case. In the first case, two nodes are adjacent if linked by a reciprocal link, representing two individuals participating at the same event. In the second case, two nodes are adjacent when a directed link connects the same actor joining in different events. Directed lines, as a consequence, specify the sequence of events with arrows pointing towards a progressive time development, starting from the first and finishing with the last event. While reciprocal ties capture joint attendance at events, directed ties follow the person-specific participation in events over time.

\section{Knowledge and Experience}

We start by observing that actors attending events gain some knowledge from the event. The event could be an explicitly informational or training event, in which case it is clear that attendance has meant that participants have gained some new information. Alternatively the event could be an activity or a game in which case the experience gained by participating will also contribute to knowledge. We shall call the information gained by an actor from attending a "network event experience" or simply "experience" for short. We use the term "network experience" to emphasize we are only looking at information gained from participating in the event.

There is a second opportunity for actors to gain information from an event. We shall assume at an event actors exchange information with other actors at the same event. Part of what they exchange is network experience they have from previous events they have attended. As a consequence an actor who did not attend an event may gain information from another actor who was at the event, i.e., their network experience, when they both meet at a later event. Even if both actors attended both events they still may gain additional information about the earlier event from each other when they meet at a subsequent event. We shall call information that an actor 
gains from other actors who attended a previous event "network knowledge". Again we use the term network knowledge to emphasize we are only looking at knowledge gained from network activity and not any external knowledge an actor may bring. To summarize experience is gained at an event from the event itself, once this is passed on it becomes knowledge to the receiver. When considering any transfer of experience we shall call it knowledge.

Our interest is in developing a purely structural measure which tries to capture the opportunity for actors in a network to gain information by directly experiencing an event and by learning from other actors who attended other events. Although we do not use the term this could be seen as a centrality type measure. The presented new measure clearly differs from well-known measures of centrality in a number of ways. Primarily, the proposed measure is innovative because it specifically applies to two-mode temporal networks, rather than using the one-mode projections of a two-mode matrix. By using the BDLG as a starting point, in fact, original twomode networks are represented in a manner that directly focuses on both modes composing the affiliation network, e.g. individuals and events. The importance of this dual focus, widely discussed in the literature (Breiger, 1974; Faust, 1997; Diani, 2015; Everett, 2016) calls for new centrality measures that simultaneously combine the dependence of individuals and events and vice versa. This new measure does this since it jointly considers the effect of both network entities, that is actors and events, in determining network knowledge and experience of individual actors.

\section{Towards an Algorithm: Assumptions behind this new measure}

Through face-to-face and hands-on experiences individuals interact and in so doing tend to share information and skills. Here, shared participation is intended as a social mechanism that explains how people learn, gain experience, and adopt practical knowledge to perform their tasks. By collaborating with each other through face-to-face interactions, individuals who already possess certain skills and knowledge pass these to other participants. In this way, people can consolidate their abilities and gather new practical knowledge to be potentially used in future tasks during each activity/event they attended. From a modeling perspective, these social dynamics require a model that captures the importance of past relationships and past attendance to events and is also able to simultaneously examine hands-on experiences and face-to-face interactions as channels of knowledge transmission. Starting from the bi-dynamic line-graph representation, the proposed measure captures both these mechanisms and quantifies the amount of practical knowledge individuals acquire through these two channels.

In the following section, we outline the assumptions for the individuals and events which will form the basis of the knowledge and experience measure. These assumptions are important for defining a measure that rules out other potential measures that would result in unrealistic or absurd consequences. 
Network boundaries: we are only concerned with knowledge and experience generated and transmitted within a specified set of actors. Clearly there is potential for actors to bring in additional knowledge from outside the set but that is not what we intend to measure.

Referring to individuals, it is formally assumed that:

Individuals who attend an event have a unique experience. Different individuals attending the same event and undertaking activities learn different things based on their previous experience and abilities. As a consequence two individuals who attend the same event and meet again later at a different event can exchange additional information about the first event that adds to their network knowledge. This condition can easily be relaxed or modified if it is deemed unrealistic or too restrictive.

Individuals attending an event share with others some of the experience and knowledge they previously gained at other events. Individuals who meet others that already possess some experience from previous events gain some of their knowledge. Note it is assumed that individuals share with others only some of their previous knowledge gained within the network. This limitation reflects the idea that events only last for a specific length in time and therefore experienced individuals tend to select a small subset of information that they want/need to pass to others. In addition receiving individuals will only retain some of the passed on information.

Individuals do not learn the same thing nor share the same information twice. For each event, individuals increase their knowledge and experience by learning something different. Of course individuals may forget something they have learned and have to relearn this. However the re-learning experience is different and will not necessarily require an interaction with any of the original actors.

Individuals attending their first event do not have any knowledge or experience to share. Individuals who attend an event for the first time have no network experience and so do not have any information to transfer to others. (If there were a previous event that individual share information about, then we can simply insert this event as event 1 . Each node can be given their own starting event to represent their unique life experience to that point.) This assumption derives from the fact that, at this stage, the algorithm only considers the knowledge transfers inside the network and not from the outside.

Individuals can only attend one event at time. It is assumed that individuals cannot attend multiple events simultaneously. Of course if they do the events can be broken down into sub-events and the condition can be made to hold true.

For events, it is assumed that: 


\section{Events are chronologically ordered.}

Events happen at a specific point in time. The duration of events is not taken into account, although this is easily relaxed.

Events are mechanisms which impart information or experience to the participants.

Given these assumptions it is clear that the measure is very different from any of the standard centrality measures. A fundamental difference is that the measure takes account of the time progression. Since flows are dynamic and evolve over time, quantifying an individual score requires appropriate computational adjustments in order to take into account how the flow under examination develops. Our measure includes the time dimension since it is based on the BDLG configuration that, by construction, incorporates the time into the graph. As such, edges among nodes are dependent on the temporal growth of the networks and are not retroactive. In particular, the model distinguishes the temporal aspect in two ways: the temporal proximity and the temporal sequence. The temporal proximity is represented by undirected ties, whereas the temporal sequence is anchored to directed ties. While undirected edges connect different individuals attending the same event, directed links show for each individual a track of his/her attendance in events over time and generate paths that follow the individual histories of participation.

Similarly to information centrality (Stephenson and Zelen, 1989) and the well-known flow betweenness (Freeman, Borgatti and White, 1991), the knowledge flow measure considers the issue about the routes through which information is disseminated among all pairs of nodes, but it does it in a different way. Information can flow not only along "optimal" paths connecting each pair of nodes, but it is more realistically embedded in several routes that need to be taken into account.

Finally, this new measure considers the effect of every intermediary node along each possible path connecting two pair of nodes. This is a consequence of the fact that individuals share both their experience (what they got from attending the event) and their knowledge (what they learnt from other actors attending the event). So that if actor $\mathrm{x}$ and actor $\mathrm{y}$ attended an event actor $\mathrm{x}$ may share with $\mathrm{y}$ information gleaned from $\mathrm{z}$ who was also at an event with $\mathrm{x}$. In addition $\mathrm{z}$ may have got that information from another actor and hence the information travels through a variety of paths within the network.

\section{The Algorithm}

We begin by giving a sketch of the algorithm. It is based on an accumulation of points where the points are meant to represent information. A very simple measure for the accumulation of points would be to let the points after event $t$ for person $i$ be a weighted average of the points of the people with whom i co-participated in e, $Z_{\mathrm{i}, t+1}=Z_{\mathrm{it}}+\rho \sum_{\mathrm{j}-\mathrm{t}} Z_{\mathrm{jt}}$. As we shall see, the implied assumptions of this manner of accumulation would not be in accordance with the assumptions 
above and lead to implausible consequences. To be consistent with the more realistic assumptions, a more involved algorithm is needed.

When an actor attends an event they gain one experience point. It follows that in the two-mode representation of the network, an actor's degree equals the number of experience points they earn. This is equivalent to the length plus one of the directed path from a source to a sink in the BDLG where we only traverse the directed edges.

When two actors attend an event then they exchange information. This information is the sum of their experience and their knowledge attenuated by some factor which, for the sake of illustration, we set at 0.5 . The pair of actors can only exchange knowledge they have not exchanged before. So for example suppose actors $\mathrm{x}$ and $\mathrm{y}$ meet at two events and they are the only participants at these two events and $y$ is attending their first event and so has no knowledge or experience. On the other hand suppose $x$ attends the first event with 1.6 units of information (that is knowledge plus experience). At the first event $y$ will gain half of $x$ 's information plus their own experience so will leave the event with 1.8 units of information. When they meet at the next event, $x$ now has 2.6 units of information as they gained an extra unit from the event they attended with $y$, but they have already shared 0.8 with $y$ and so has 1.8 units of new information. In this case $y$ gains half of this plus another experience unit so ends the event with 3.7. The situation is more complicated when a number of actors are at the same event as it becomes necessary to trace all the information between all the actors to make sure something is not learnt twice. This is captured in the following algorithm.

We shall start by indexing the event sequence by $\mathrm{K}$ and the algorithm starts by setting $\mathrm{K}=2$, the second event; this is because at the first event actors have no knowledge to share but all gain an experience point. Then, it considers the knowledge exchange for each pair of actors $i$ and $j$ step by step throughout all events. For each step, it calculates how much of the experience each individual $i$ at the event $\mathrm{e}_{\mathrm{k}}$ pass to every other individual $j$. It should be noted that $i$ does not have to attend event $e_{k}$ as their experience can be passed on by others. To capture this the algorithm tracks all possible acceptable paths for each pair of vertices $\mathrm{ie}_{\mathrm{k}}, \mathrm{je}_{\mathrm{k}}$. Here a path is defined as a set of adjacent edges from $i$ to $j$ which do not pass through the same node twice (Borgatti, Everett and Johnson, 2013:15). We consider as 'acceptable' a path that comprises of a sequence of adjacent nodes $i_{\mathrm{k}}$, that starts with an undirected link $\left(\mathrm{ie}_{\mathrm{x}}, \mathrm{je}_{\mathrm{x}}\right)$ and does not contain undirected links. The length of an acceptable path corresponds to the number of undirected links $\left(\mathrm{ie}_{\mathrm{x}}, \mathrm{je}_{\mathrm{x}}\right)$ it contains. The following figure 2 may help clarify the meaning of acceptable paths.

[Figure 2 about here] 
At this point, the algorithm weights each path with a score representing the amount of knowledge $i$ passes to $j$ through the given path. It calculates the total knowledge transferred $\mathrm{Z}$, as the knowledge owned by vertex $i_{k}+1$. Then, for each path placed in the list, the algorithm counts the total amount of knowledge held by $\mathrm{ie}_{\mathrm{z}}$ without considering the knowledge actor $i$ already passed to $j$ during the previous $\mathrm{e}_{\mathrm{k}}$ event and by dividing it by 2 since conventionally it is assumed that actor $i$ passes only half of its knowledge to someone else. Note that, the total amount of knowledge $i$ gives to $j$ decreases as paths are considered. In addition, since it is assumed that individuals do not learn a same thing twice, the knowledge $i$ passes to $j$ at $\mathrm{e}_{\mathrm{z}}$ event does not contain the knowledge $i$ had passed to $j$ already. This mechanism is repeated until all acceptable paths between all pairs of nodes have been found and all events considered. Given $n$ actors and $m$ events arranged in sequential order the general form of the algorithm is the following:

(1) Transform a two-mode network into a bi-dynamic line-graph and set $L(i, j)=0$.

(2) For $i=1$ to $n$

(3) For $\mathrm{j}=1$ to $n$

(4) For $\mathrm{k}=2$ to $\mathrm{m}-1$

(5) For $\mathrm{s}=1$ to $\mathrm{n}-1$

(6) Find all acceptable paths of length $\mathrm{s}$ from iek to nodes of the form jet

(7) $p=$ number of nodes of the form ieq where $q<t$

(8) For each acceptable path

(9) $\mathrm{L}(\mathrm{i}, \mathrm{j})=\mathrm{L}(\mathrm{i}, \mathrm{j})+(\mathrm{p}-\mathrm{L}(\mathrm{i}, \mathrm{j})) / 2^{\wedge} \mathrm{s}$

(10) next path

(11) next s

(12) next k

(13) next j

(14) next i

On termination the matrix $\mathrm{L}(\mathrm{i}, \mathrm{j})$ gives the amount of knowledge actor $i$ passes to actor $j$.

\section{A simple example}

As an example, consider the bi-dynamic line-graph in figure 1. We want to measure how much knowledge actor 2 is passing to actor 3 . The acceptable paths connecting actor 2 and 3 are: path 1) from $(2, \mathrm{e} 2)$ to $(3, \mathrm{e} 2)$ and path 2$)$ from $(2, \mathrm{e} 4)$ to $(3, \mathrm{e} 4)$. Through path 1$)$, actor 2 , who acquired experience equal to 1 by taking part at the event at time 1 , shares with actor 3 part of this at the second event that both are attending. With path 2$),(2, \mathrm{e} 4)-(3, \mathrm{e} 4)$, actor 2 passes to actor 3 half of their knowledge they acquired by attending two events minus what they already passed through the previous path. Figure 3 visually represents those paths. 
[Figure 3 about here]

Now, consider actor 2 and actor 5 . How much knowledge actor 2 is passing to actor 5 ? In this case, there are three acceptable paths, as it is shown in the next figure 4 below.

[Figure 4 about here]

In this case, through path I actor 2 gives to actor 50.25 units of knowledge. This is due to the fact that actor 2 is not directly connected to actor 5 . Actor 2 is passing knowledge to actor 5 through actor 3. Path II is similar to path I to the extent that actor 2 is passing his knowledge to actor 5 through actor 3 . In this case, the amount of shared information does not include the knowledge that has been counted with the previous path I. Finally, through path III actor 5 receives 0.78125 units of knowledge from actor 2 . This is equal to half of the experience actor 2 acquired by attending two events, (events one and two) without including the units of knowledge that actor 2 already gave to actor 5 through the previous two paths.

Table 1 shows all acceptable paths that have been found among each pair of nodes in this example together with the number of units that the path contributes.

[Table 1 about here]

The matrix in figure 5 presents the learning matrix $L$ that is derived from the application of the algorithm. The number of rows and columns correspond to the number of actors in the dataset. The scores in each matrix cell record information about the total amount of knowledge shared between each pair of actors through the acceptable paths. The L $(i, j)$ data entry gives the total units of knowledge that actor $\mathrm{j}$ received - via all possible paths -- from actor $\mathrm{i}$. It follows that the row sums correspond to the total 'knowledge given' of an actor and the column sums correspond to the 'knowledge received'.

[Figure 5 about here]

Since it is assumed that knowledge flows through paths, the knowledge given and knowledge received scores are seen as indices of the exposure of a node to the network flow. By ranking the actors on the basis of those results, we obtained the results presented in table 2 .

[Table 2 about here]

Actors 3, 2 and to a lesser extent actor 4, have the greatest knowledge given scores, and might be identified as the individuals who mainly played the role of mentors and instructors. Actor 5 and 6 , instead, seem to be the individuals who mostly benefitted from this flow of knowledge. It is interesting to compare these results with a simple degree measure. In this network actors 1 and 6 have degree 1, actors 4 and 5 have degree 2 and actors 2 and 3 have degree 3 . The highest 
degree actors are highest on knowledge given as would be expected as by attending all but one of the four events each they will acquire experience which can then be passed on as knowledge. However we note that actor 5 is top of knowledge received and that actor 4 is second from bottom but they both had the same degree. To illustrate the difference between this method and other centrality measures consider a network of 4 actors and 6 events with each actor attending 3 events. Suppose 1 attends events A,C and E; 2 attends events B,D and F; 3 attends A,B and C and 4 attends D,E and F. Each event is attended by two actors and obviously each actor has the same degree. If the events occurred in alphabetical order then actor 4 would have the highest knowledge received and actor 3 the highest knowledge given. If we reverse the order then 3 has the highest received and 4 the highest given. In fact, we can permute the orders of the events so that any specific actor has the highest given or received scores, but this permutation is an isomorphism and so would not affect any purely structural measure. This property demonstrates how different the measure is from all standard centrality measures, which would be invariant under the permutation.

One of the issues with the algorithm as outlined above is its computational complexity. Since it involves searching a graph for all possible paths, it has exponential time complexity and is very inefficient. This is compounded by the fact we use a line graph and so the number of vertices is equal to the number of edges in the original two-mode network. It is possible to reconfigure the algorithm so that it works on the original two-mode network and although the cost savings are not insignificant they still will not be sufficient to have a workable algorithm in a lot of cases. A second modification would be to restrict the length of acceptable paths, $\mathrm{p}$ (that is undirected links), to just two or three. Since increasing the value of $p$ halves the contribution then paths longer than three have minimal effect. Again this would increase the size of problem that could be managed but there still could be a large number of paths to consider.

An alternative approach is to simulate what is happening. When an actor attends an event they distribute any points they have to other actors at the same event. If they meet one of these actors again at a later event then they again distribute some of the points, but as in the algorithm above they do not give away the points twice. After an event, an actor receives extra points for attending the event. In order to make the algorithm run faster we only use integer arithmetic but we can use large integers in order to get greater accuracy. We shall describe how this works by tracing through a few steps for the example given in Figure 1 assuming each actor gains 1,000 points of experience at each event they attend. Hence at event 1 actors 1,2 and 4 all gain 1,000 points. At event 2 actor 2 comes in with 1,000 points and passes 500 of these to actor 3 . Hence after event 2 actor 2 has 2,000 points and actor 3 has 1,500 points. Rather than trace what happens to every actor after each event we will just illustrate the knowledge that actor 5 gains from actor 2 . Actor 5 attends event 3 and actor 3 is also at event 3 . As already noted actor 3 gained 500 units of knowledge from 2 at event 2 . Hence they can pass half of this at event 3 on to 5 , so that after event 3 actor 5 has 250 units of knowledge from 2. Moving to event 4 we see 
that 2 is at the event and so can directly contribute some of their experience to 5 . At this point 2 has 2,000 units but 5 already gained 250 units from 2 via actor 3 at event 2 . Hence 2 has 1750 units they could pass and so pass half of these to 5 , that is 875 . We also see that 3 is again at event 4 and so can pass some of their knowledge they gained from 2 on to 5 . They had 500 units and passed 250 of these on at event 3 and so only have 250 to pass on. But half of these 250 would have been passed directly to 5 from 2 and so 3 only has a potential of 125 units. If they pass half of them they end up passing 62 units at event 4 . It follows that the total 5 gained from 2 is 875 directly from 2 and $312(250+62)$ via 3 giving a total of 1187 .

We note this value is not quite the same as the first algorithm which gave a value of 1.22. The reason for the difference is firstly the algorithm treats the longer paths in a slightly different way and takes more account of the path history. This is ignored in the simulation based approach. One other major difference is the order in which the exchanges are made will affect the results marginally. The algorithm orders the exchanges by path length whereas the simulation based approach merely does the direct exchange first and the others in the order they are listed. The simulation could be adjusted to give a closer agreement but at a computational cost. The full results for the simulation based approach on the example of Figure 1 are given in Table 3. The diagonal elements give the experience gained by attending an event and the off diagonal elements in row $\mathrm{i}$ column $\mathrm{j}$ give the learning that $\mathrm{j}$ acquired form $\mathrm{i}$.

[Insert Table 3 about here]

It should be noted that this algorithm gives very similar results to the BDLG algorithm but as already noted will differ slightly on more complex paths. Of the 30 possible entries in the off diagonal the 16 zeros agree and 12 of the 14 other values are in exact agreement. Just two values are different and the largest of these two is under 3\% different. It should be noted that this difference only occurs with the longer paths and as these have less effect by design the differences in the two approaches is very small and so is not an issue in looking at any real data. This algorithm has been implemented in UCINET (Borgatti, Everett and Freeman, 2002) where it can be found in the command line interface (CLI) and has the syntax: Expflow(dataset probability_points), where dataset is a 2-mode dataset in which the columns (events) are presumed to be in chronological order.

The simulation algorithm has a similar feel as an agent based model. Clearly this approach could be embedded in a full scale agent based model in which the simple rules we have suggested could be captured in a more nuanced way. Our simulation is an attempt to find a scalable algorithm to represent a structural deterministic approach and not to embed rules in agents. We see our approach as an extension of the Borgatti (2005) centrality and flow paper rather than as an agent based model (ABM). It would be interesting to extend this approach to an ABM by using a platform such as Repast (North et al 2006) or CONSTRUCT 
(http://www.casos.cs.cmu.edu/projects/construct/index.php) but we do not explore this opportunity here as we are concerned with a deterministic structural algorithm.

In the next section, we present the knowledge and experience measure results for two real-world networks using the simulation based algorithm.

\section{Applying the knowledge and experience measure to real data.}

Our first example is the well-known Southern Women Data collected by Davis et al (1941). In Table 4 we give the knowledge received, the knowledge given and the sum of the two for each of the women. Note we have not included the experience which of course is simply the degree in the two mode network and that can be added to the knowledge received if required. We have used the standard data as given in the original source and widely available in software packages such as UCINET (Borgatti et al 2002). Note the events are not given in the order they occurred in this data but this information is in the source data. The order of the events are E11, E5, E2, E7, E12, E9, E3, E6,E10, E1, E14 E8, E4 and E13. These occurred during a 9 month period starting on the $23^{\text {rd }}$ of February 1930 with the last event on the $21^{\text {st }}$ of November.

[Insert Table 4 about here]

We note that for knowledge received the scores are fairly similar with the exception of Olivia and Flora. For the knowledge given there is a far wider spread and differentiation amongst the actors. Freeman (2003) provides a meta-analysis of a large number of techniques designed to find groups in the Davis data. In addition he examines the core and peripheral members of each group. In Freeman's analysis the top four women in one group are Theresa, Brenda, Evelyn and Laura and for the second group Sylvia, Nora, Katherine and Helen. If we sum knowledge given and received as shown in column 3 of Table 4, then we find these 8 women have the top eight scores, providing some level of agreement at the aggregated level. This is also true if we just looked at the given scores; this is to be expected as we would expect core members of the group to be those giving knowledge. Freeman identifies 3 peripheral women in each group namely Eleanor, Ruth and Pearl in one group and Dorothy, Olivia and Flora in the other. Again looking at the sum we see that four of these women have the lowest scores but Charlotte and Frances have replaced Eleanor and Ruth. The same is also true for the just the given scores. One of the issues with the Freeman analysis is that the core and peripheral women are within groups and not overall. Everett (2016) has given an analysis of the centrality of the women and the events using a dual projection approach and compares this with some of the standard two-mode centrality methods. There is more or less universal agreement about the top actors and nearly all the measures agree with the Freeman core women. It is also true that at the bottom end nearly all methods place Olivia, Flora and Dorothy at the bottom (the one exception is Dorothy is fourth 
from bottom on two-mode closeness). In our analysis we see that Dorothy has a very low given score but a received score that is similar to all other women except Olivia and Flora. All three women attended two events but Dorothy attended events E8 and E9 whereas Olivia and Flora attended events E9 and E11. Recall that E11 is the first event whereas E8 occurred much later in the year. This gives Dorothy the opportunity to capitalize on the collective experience of everyone at that event and so pushes her received score up so that it is comparable with the others. While the Southern women data is well known and we are able to reproduce similar findings to other analyses it is not really the type of data that allows us to demonstrate the effectiveness of the method. We now look at a second example, the Noordin Top network in which knowledge transfer is of greater importance.

The Noordin Top network is based on a dataset accumulated over 6 years, from 1999 to 2005, involving 79 individuals who attended in total 50 events classified as either meetings, training camps or operations such as bombing attacks and robberies. The data set was first reconstructed by Sean Everton and his colleagues Nancy Roberts and Daniel Cunningham from the International Crisis Group report[1]. The data set is publicly available and downloadable from Everton's website[2]. For the purposes of this paper, we used the two-mode networks reconstructed by Everton (2012). In particular, we collapsed and aggregated three separate twomode matrices. The first one referred to 79 individuals attending 20 meetings, the second matrix referred to the same 79 individuals participating in 16 training camps and the third one comprised these 79 individuals carrying out 14 violent attacks. The resulting two-mode matrix is of 79 individuals and 50 events. In addition, for each event we obtained the exact time at which the event took place. This information was found in the International Crisis Group report, or, when absent, in online articles [3]. Due to the media coverage of Noordin Top activities, some events were also reported in the news, making it easy to identify in many cases the exact date of the event when time information was missing in the original report. Having obtained this information we are able to place the events in time order as required by the algorithm.

Figure 6 represents Noordin Top network through the BDLG data representation.

[Figure 6 about here]

The BDLG represents the temporal progression of militants' engagement in covert actions. Starting from left to right, each group of nodes represents an event and the corresponding individuals attending it. The type of events is indicated by the shape of nodes: Training camps are represented as squares, meetings as triangles, and bombing and other general violent actions such as robbery are represented as circles. These events follow the temporal order, and the number on top of each cluster reveals the ID of the event. Note that event (9) is missing. This is due to fact that no one had been identified as attending this particular event. Similarly, the 
fourteen individuals who have not been associated with any event have been omitted from the graph. The removal of isolates is automatically produced by the BDLG representation because in order to represent an edge as a node it requires an individual linked with an event in the original two-mode data. Specifically, the figure reports the real date for the main bombing attacks occurred during the whole temporal window (12 October, 1999 - 1 October, 2005). The trajectories in red, green and sky blue refer to the most central individuals, in line with the onemode degree centrality results (omitted). The criminal career of Noordin Top is represented by the line in red. The other two lines - green and blue - represent the criminal career of, respectively, actor (23) and actor (45) who, were the closest accomplices of Noordin's due to their role of technician and trainer. Finally, the black circular nodes, clearly noticeable in the representation, indicate the exact event in which these individuals became suicide bombers. Due to missing information, not all suicide bombers have been identified. However, this type of information is useful since it makes clear that for them any other event would have been precluded.

In general, the BDLG gives an image of the rate of individuals' turnover participating in events over time. It offers new insights about the pattern of interactions without arbitrarily distinguishing the whole time window in adjacent temporal intervals. By looking at who joined the actions, at which point in time, and with whom, it is possible to track individuals' careers and provide information about the hidden organisation and its structural dynamics[4].

[1] The narratives about Noordin's network and activities presented in this paper are not based on Everton's book (2012). Mainly, we referred to the original International Crisis Group Report. Using International Crisis reports for academic purposes is not new. An example comes from Sageman (2004) who similarly interpreted his results on the light of the information reported in one of the International Crisis Group documents.

[2] https://sites.google.com/site/sfeverton18/

[3] References provided on requests.

[4] Note that all the visualisations in this paper are constructed by using VISONE Software for Visual Social Network Analysis, version 2.16. Available at: http://visone.info/html/download.html. Last access: 13 August 2016.

\subsection{Results}


The results for the individual rankings are displayed in Table 5 for the knowledge given scores and in Table 6 for the knowledge received scores Actors, identified by their ID, are listed in descending order of knowledge. For ease of interpretation, for each actor we only highlight the largest value of the two knowledge given and received values, and the lower one has been greyed out. These scores indicate how individuals are positioned with respect to the flow of knowledge dissemination by considering the amount of knowledge they passed (acquired) to (from) someone else. Actors with higher scores in knowledge given are the most active in passing their knowledge to others, whereas individuals with higher scores in knowledge received correspond to militants who mainly benefitted from this knowledge transfer. If Table 5 identifies which individuals assumed a mentorship role, Table 6 lists the ones who absorbed most of this knowledge. We also provide context to these results in order to offer further interpretation by referring to the description of the individual's roles presented in the International Crisis report, some of which is summarised in the column 'Role' in Tables 5 and 6.

[Table 5 about here]

[Table 6 about here]

Noordin is top on knowledge given (339.624) whereas he is ranked 8 on knowledge received (90.089). This result is not surprising since Noordin Top was the principal organiser of all the bombing attacks. Actor (23) and actor (45) are ranked, respectively, 2 and 3 on knowledge given with (294.187) for the former, and (293.108) for the latter. Both operatives helped Noordin by providing their knowledge as master-bomb technician and suicide recruiter. Next, moving down the scores, we find (77) (72) and (61). Actor (77) helped Noordin in involving actor (45) for the Australian embassy bombing operation on 2004. It was through actor (77) that actor (45) got involved in the Noordin-led Australian embassy bombing operation in 2004. Actor (77) frequented an-Nur Universitas and he presumably met the famous military instructor (45) when he came to this University in order to enroll his brother (International Crisis Group, 2006:8). Actor (77) was also really close to Noordin with whom he was engaged in long discussions about the necessity to fight with the U.S. and its allies in Indonesia. The importance of actor (72) is due to his participation at the Christmas Eve bombing on 2000. He asked Noordin to use the leftover explosives for carrying out another bombing attack. Actor (72) can be considered a person experienced in moving explosives since he also was responsible for 'getting the explosive from Dumai to Bengkulu via Pekanbaru, safely as unaccompanied baggage on an ordinary intercity bus' (International Crisis Group, 2006:4). Actor (61) was an instructor, with planning and logistic expertise, but his relations with other operatives is not well-documented in the International Crisis report. Another interesting result from this list is related to actor (8) ranked 10 on knowledge given. He was a well-known JI East Java member and lecturer at an-Nur Universitas, in Solo. Actor (8) was instrumental for Noordin's plans not only for recruiting operatives among his students, but also as a 'mentor of several of Noordin's young Central Java followers' (International Crisis Group, 2006:14). 
Results in Table 6 reveal that actor (64), (18), and (50) are on top on knowledge receivedreceived. These three individuals were all directly related. Actor (18) was originally asked to be the fourth suicide bomber, 'but he was an Ambon veteran, and actor (23) reportedly decided that he was needed to train others' (International Crisis Group, 2006:18). Actors (64), (50) and another operative (not included in this network) become the suicide bombers in Bali bombing II. Due to actor (45)'s arrest in November 2004, these suicide bombers were subsequently trained directly by Noordin 'on the second floor of the 'Selera' restaurant in Semarang' (International Crisis Group, 2006:18). Moving on, actor (24), ranked 4, was a close associate of Noordin and received instruction directly by him in order to provide additional religious support to the suicide bomber candidates for the Australian Embassy bombing in 2004. Actor (46) has also a high score in knowledge received (he is ranked 5). He was a direct student of actor (23), the bomb-maker instructor.

Overall, there is a great deal of similarity between knowledge given/received scores and the information about the individual's roles and positions reported in the International Crisis document. Tasks and responsibilities played by individuals seem to explain and quite well justify the ranking positions. Essentially, scores tend to reflect what operatives were actually able to give and/or receive. It might not be a coincidence that the top positions in the knowledge givenranking are occupied by actor (23), the master bomber technician, and actor (45), the suicide bombers' instructor. Following these, there are university teachers, well-known bombers who took part in the first Bali bombing attack in 2002, leaders of small autonomous commands, and those responsible for moving and securing the explosives, all of which resulting in high knowledge of experience given scores. Top positions in the knowledge receivedreceived measure are, in turn, occupied by individuals with other types of responsibilities. For example, almost all suicide bombers appear in this table as well as actor (23) and (45)'s students. In addition, the list comprises also the operatives who primarily helped to hide Noordin and his closer accomplices, and Noordin's information couriers.

\subsection{Discussion}

Knowledge given and knowledge received scores are consistent with the hypotheses for individual centrality stated in the literature of covert networks. Individuals with the highest scores in the knowledge given, e.g. Noordin Top, actor (23) and actor (45), were actually the most active (Khadka et al., 2013), with important skills - bomb technician, military trainer, bomb disposal experts - (Bouchard, 2007), and authority - university lectureships - (Varese 2012), who also had influential roles within the network (Xu and Chen, 2003; Malm and Bichler, 2011; Walther and Christopoulos, 2014; Campana, 2015). The high centrality of those individuals also emerged as a problematic aspect since their high visibility increased their vulnerability. Similarly to what has been argued in the literature, the International Crisis report 
suggests that individuals with highest centrality need to amplify their efforts in order to remain hidden and maximize their security (Sparrow, 1991; Carley, Lee and Krackhardt, 2002; Raab and Milward, 2003; Milward and Raab, 2006). Interestingly, this dark side of individual centrality clearly appeared by looking at the individual task distribution listed in the knowledge receivedscores. It might not be a coincidence, in fact, that many of those individuals are reported to having hidden Noordin and his closer accomplices to reduce their risks of being arrested by the police.

In accordance with the literature on centrality flow (Borgatti, 2005; Borgatti and Lopez-Kidwell, 2009), these results provide empirical evidence that individuals assume a central position by virtue of what they receive and pass on through the network by interacting with others. In particular, knowledge receivedg scores seem to suggest that the more individuals acquire knowledge from mentors, the likelier those individuals become central within the network. The exchanges among mentors and apprentices all throughout the time window seem to confirm the importance of mentors in providing a fundamental contribution to the individual criminal career development (Sutherland, 1937; Shaw, 1981; Morselli, Tremblay and McCarthy, 2006). In addition, these results appear to be in accordance with what is argued in the literature on network flow that individual centrality not only depends on how individuals are positioned within the flow, but it also depends on the type of flow itself and its specific channels of propagation (Borgatti, 2005). We may note that individuals who become suicide bombers, bomb makers and information couriers were the ones who received the most crucial knowledge, differently from the actors who provide Noordin with minor help, and that, presumably, only had a limited access to information. In this case, tactical knowledge, military skills, commitment to the jihad were all different types of expertise able to reinforce the individual criminal careers. These results seem to lend support to the theoretical hypotheses following which learning mechanisms activated by joint tasks not only favour the optimisation of resource (Bright, 2015), but they also positively affect the individual criminal career by consolidating their criminal repertoire (McGloin and Nguyen, 2014). Therefore, the idea of criminal capital seems to fit here perfectly (McCarthy and Hagan, 1995). Joint activities are the optimal channels that provide opportunities to individuals to enhance their roles as operatives (Baron and Tindall, 1993), becoming proactive (Sarnecki, 1990, 2001) and gaining the necessary 'know-how' expertise and practical capabilities to carry out violent attacks (Forest, 2008; Kenney, 2008; Gerdes, 2014). In other words, it seems that the type of information, such as functional abilities (making a bomb), knowledge of the internal hierarchy, or assuming a role (becoming suicide bomber) affects the mechanisms of criminal capital dissemination, and the individuals' possibilities to assume central roles in this process dissemination.

\section{Conclusion and Future steps}


The main purpose of this article has been to introduce a new measure of knowledge and experience flow in order to be able to capture an actor's position within the flow of knowledge dissemination. This new measure returns two scores for the individuals involved in the network: one is related to the knowledge passed on from experienced person to others, and one concerns the complementary process of acquiring this knowledge. Although the different diagnostics of individual's centrality are not meant to be interpreted literally, this measure has been shown to be realistic in practical applications although more needs to be done to demonstrate its effectiveness. This measure is inspired by the idea that individual collaboration nurture individuals' abilities by fostering the sharing of information, knowledge and expertise. Our simulation study demonstrated the innovative potential of the proposed measure in capturing the prominence of individuals within the two processes of learning and knowledge sharing for covert networks.

This measure offers important contributions for illuminating the dynamics among collaboration networks for example within the academic environment or within business or any area where information is flowing.

To conclude, the proposed measure in its current state of development calls for at least three types of refinements. Firstly, more work needs to be done in the direction of tailoring the initial assumptions in different scenarios such as the case in which individuals are invited to be part of the network by virtue of their experience which they are asked to share. At the moment individuals are arbitrarily considered without knowledge to share at the beginning. Secondly, further elaborations of the proposed measure might control for the size of the events since it can be reasonably thought that the more the number of individuals attending an event, the less opportunities they have to share their knowledge with everybody else. In doing this full consideration would need to be given as to the opportunities actors have for attending events and for how the size of events are controlled. Finally, other developments may introduce a sort of decay factor. Individuals who attended many events closer in time might be likely exposed to similar information, resulting in a less motivation in absorbing it. 


\section{REFERENCES}

Baron, S. W. and Tindall, D. B. (1993) 'Network structure and delinquent attitudes within a juvenile gang', Social Networks, 15(3), pp. 255-273.

Borgatti, S. P. (2005) 'Centrality and network flow', Social Networks, 27(1), pp. 55-71.

Borgatti, S. P., Everett, M. G. and Freeman, L. C. (2002) 'Ucinet for Windows: Software for Social Network Analysis.' Harvard: MA:Analytic Technologies.

Borgatti, S. P., Everett, M. G. and Johnson, J. C. (2013) Analyzing Social Networks. First publ. SAGE.

Borgatti, S. P. and Lopez-Kidwell, V. (2009) 'Network Theory', Science, 6(3), pp. 1-14.

Bouchard, M. (2007) 'On the Resilience of Illegal Drug Markets', Global Crime, 8(4), pp. 325344.

Breiger, R. L. (1974) 'The Duality of Persons and Groups', Social Forces, 53(2), pp. 181-190.

Bright, D. a. (2015) 'Disrupting and Dismantling Dark Networks: Lessons from Social Network Analysis and Law Enforcement Simulation.', in Gerdes, L. M. (ed.) Illuminating Dark Networks. first. New York, NY: Cambridge University Press.

Broccatelli, C., Everett, M. and Koskinen, J. (2016) 'Temporal dynamics in covert networks', Methodological Innovations, 9, pp. 1-14.

Campana, P. (2015) 'The Structure of Human Trafficking: Lifting the Bonnet on a Nigerian Transnational Network', British Journal of Criminology, (2005), pp. 1-19.

Carley, K. M., Lee, J. and Krackhardt, D. (2002) 'Destabilizing Networks', 24(3), pp. 79-92.

Davis, A., Gardner, B., and Gardner, M.R. (1941) Deep South. Chicago: University of Chicago Press.

Diani, M. (2015) The Cement of Civil Society. 2015th edn. New York, NY: Cambridge University Press.

Everett, M. G. (2016) 'Centrality and the dual-projection approach for two-mode social network data', Methodological Innovations, 9, pp. 1-8. 
Everton, S. F. (2012) Disrupting Dark Networks. Cambridge University Press.

Faust, K. (1997) 'Centrality in affiliation networks', Social Networks, 19(2), pp. 157-191.

Forest, J. J. F. (2008) 'Knowledge Transfer and Shared Learning among Armed Groups', in Norwitz, J. H. (ed.) Armed Groups: Studies in National Security, Counterterrorism, and Counterinsurgency. Newport, Rhode Island: U.S. Naval War College.

Freeman, L. C., Borgatti, S. P. and White, D. R. (1991) 'Centrality in valued graphs: A measure of betweenness based on network flow', Social Networks, 13(2), pp. 141-154.

Freeman, L. C. (2003) Finding social groups: a meta-analysis of the Southern Women data , in Dynamic Social Network Modeling and Analysis ed R Breiger, K Carley and P Pattison Washington, DC: The National Academies Press pp 39-77.

Gerdes, L. M. (2014) 'MAPPing dark networks: A data transformation method to study clandestine organizations', Network Science, 2(2), pp. 213-253.

International Crisis Report (2006) Terrorism in Indonesia: Noordin's networks, Asia report n.114.

Kenney, M. (2008) Organizational Learning and Islamic Militancy, NIJ Journal.

Khadka, A. G., Franzer, R. E., Thomas, M., Carasiti, J. L. and Johanna, E. (2013) 'Who Supplies Nuclear Capabilities to Iran?', in Sixth Annual Political Networks Conference, Indiana University, pp. 1-23.

Malm, A. and Bichler, G. (2011) 'Networks of Collaborating Criminals: Assessing the Structural Vulnerability of Drug Markets', Journal of Research in Crime and Delinquency, 48(2), pp. 271297.

McCarthy, B. and Hagan, J. (1995) 'Getting into Street Crime: The Structure and Process of Criminal Embeddedness', Social Science Research, 24, pp. 63-95.

McGloin, J. M. and Nguyen, H. (2014) 'The Importance of Studying Co-offending Networks for Criminological Theory and Policy', in Morselli, C. (ed.) Crime and networks. first. New York, NY: Routledge, pp. 13-27.

Milward, H. and Raab, J. (2006) 'Dark Networks as Organizational Problems: Elements of a Theory', International Public Management Journal, 9(3), pp. 333-360. 
Morselli, C., Tremblay, P. and McCarthy, B. (2006) 'Mentors and criminal achievement', Criminology, 44(1), pp. 17-43.

North, M.J., Collier, N.T. and Vos, J.R., (2006). Experiences creating three implementations of the repast agent modeling toolkit. ACM Transactions on Modeling and Computer Simulation (TOMACS), 16(1), pp.1-25.

Raab, J. and Milward, H. B. (2003) 'Dark Networks as Problems', Journal of Public Administration Research and Theory, 13(4), pp. 413-439.

Sageman, M. (2004) Understanding terror networks. University of Pennsylvania Press.

Sarnecki, J. (1990) 'Delinquent networks in Sweden', Journal of Quantitative Criminology, 6(1), pp. 31-50.

Sarnecki, J. (2001) 'Delinquent Networks Youth Co-offending in Stockholm'. Cambridge University Press.

Shaw, M. E. (1981) Group Dynamics: The Psychology of Small Group Behavior. third. New York, NY: McGraw-Hill.

Sparrow, M. K. (1991) 'The application of network analysis to criminal intelligence: An assessment of the prospects', Social Networks, 13(3), pp. 251-274.

Stephenson, K. and Zelen, M. (1989) 'Rethinking centrality: Methods and examples', Social Networks, 11(1), pp. 1-37.

Sutherland, E. H. (1937) The Professional Thief. Chicago: University of Chicago Press.

Varese, F. (2012) 'The Structure and the Content of Criminal Connections: The Russian Mafia in Italy’, European Sociological Review, 29(5), pp. 899-909.

Walther, O. J. and Christopoulos, D. (2014) 'Islamic Terrorism and the Malian Rebellion', Terrorism and Political Violence, (May 2014), pp. 1-23.

$\mathrm{Xu}, \mathrm{J}$. and Chen, H. (2003) 'Untangling Criminal Networks: A Case Study', Intelligence and Security Informatics, p. 958. 

Acknowledgements: This research was supported by Leverhulme Trust Research Project Grant number R116318, PI Martin Everett. 
Table 1. List of all acceptable paths between each pair of actors.

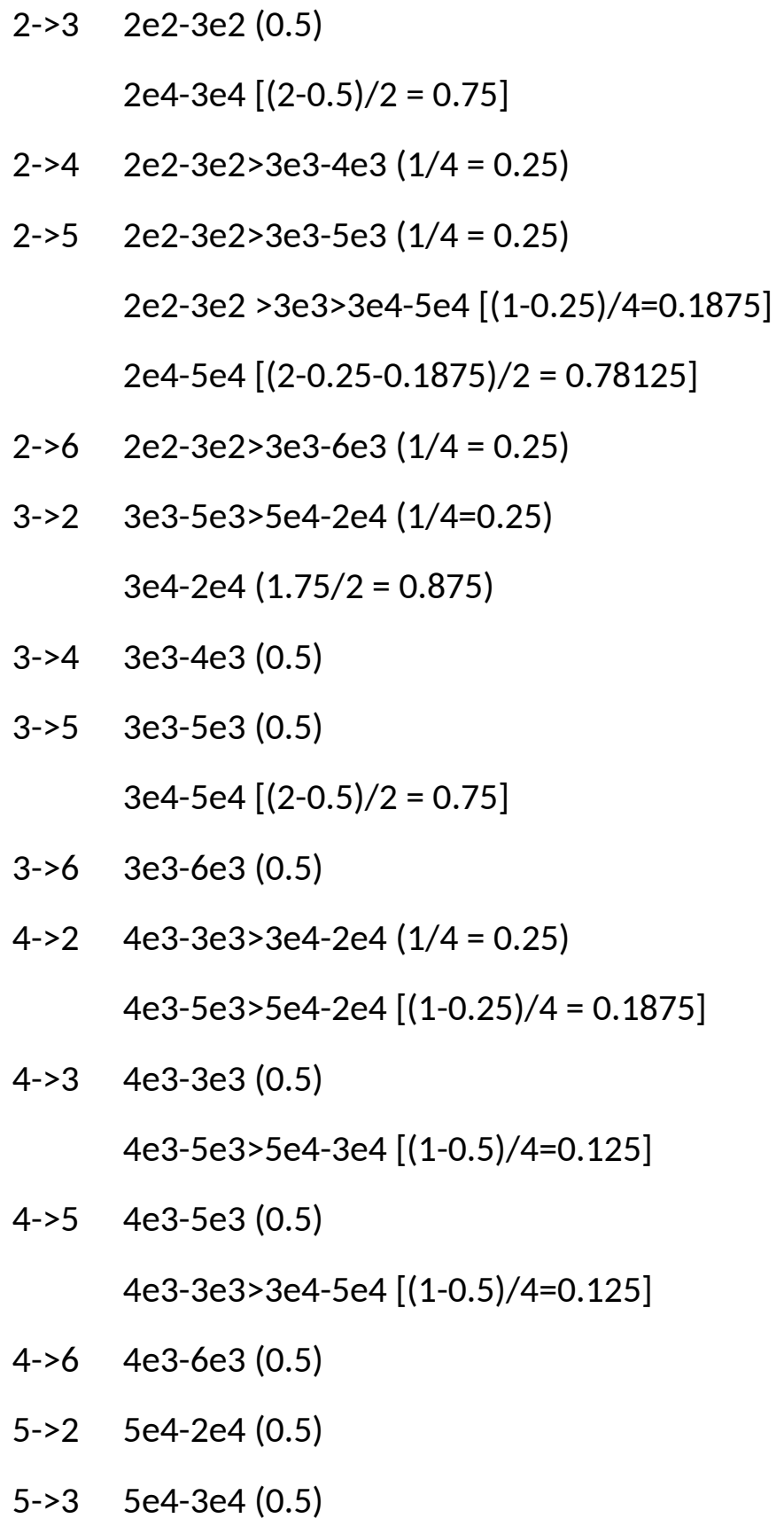


Table 2. The ranking results.

\begin{tabular}{|l|l|l|l|}
\hline $\begin{array}{l}\text { Actor } \\
\text { (Ranking) }\end{array}$ & $\begin{array}{l}\text { Knowledge } \\
\text { Given }\end{array}$ & $\begin{array}{l}\text { Actor } \\
\text { (Ranking) }\end{array}$ & $\begin{array}{l}\text { Knowledge } \\
\text { Received }\end{array}$ \\
\hline 3 & 3.3375 & 5 & 3.09375 \\
\hline 2 & 2.9687 & 3 & 2.375 \\
\hline 4 & 2.1875 & 2 & 2.0625 \\
\hline 5 & 1 & 6 & 1.25 \\
\hline 1 & 0 & 4 & 0.75 \\
\hline 6 & 0 & 1 & 0 \\
\hline
\end{tabular}


Table 3. Simulation algorithm for Figure 1.

$\begin{array}{rrrrrrr} & 1 & 2 & 3 & 4 & 5 & 6 \\ & ---- & ---- & ---- & ---- & ---- & --- \\ 1 & 1000 & 0 & 0 & 0 & 0 & 0 \\ 2 & 0 & 3000 & 1250 & 250 & 1187 & 250 \\ 3 & 0 & 1140 & 3000 & 500 & 1250 & 500 \\ 4 & 0 & 428 & 622 & 2000 & 618 & 500 \\ 5 & 0 & 500 & 500 & 0 & 2000 & 0 \\ 6 & 0 & 0 & 0 & 0 & 0 & 1000\end{array}$


Table 4 Knowledge given and received for the Southern Women Data

$\begin{array}{rrccr} & & \text { Given } & \text { Received } & \text { Sum } \\ 1 & \text { EVELYN } & 83 & 55 & 138 \\ 2 & \text { LAURA } & 83 & 49 & 132 \\ 3 & \text { THERESA } & 89 & 55 & 144 \\ 4 & \text { BRENDA } & 68 & 56 & 123 \\ 5 & \text { CHARLOTTE } & 33 & 53 & 86 \\ 6 & \text { FRANCES } & 38 & 51 & 89 \\ 7 & \text { ELEANOR } & 40 & 51 & 91 \\ 8 & \text { PEARL } & 23 & 52 & 75 \\ 9 & \text { RUTH } & 41 & 51 & 92 \\ 10 & \text { VERNE } & 41 & 51 & 92 \\ 11 & \text { MYRNA } & 38 & 52 & 89 \\ 12 & \text { KATHERINE } & 49 & 55 & 104 \\ 13 & \text { SYLVIA } & 66 & 54 & 120 \\ 14 & \text { NORA } & 86 & 48 & 134 \\ 15 & \text { HELEN } & 55 & 51 & 105 \\ 16 & \text { DOROTHY } & 8 & 53 & 62 \\ 17 & \text { OLIVIA } & 16 & 18 & 34 \\ 18 & \text { FLORA } & 16 & 18 & 34\end{array}$


Table 5. The ranking of individuals for knowledge given.

\begin{tabular}{|c|c|c|}
\hline Role & ID & $\begin{array}{l}\text { Knowledge } \\
\text { Given }\end{array}$ \\
\hline Noordin Top, network's main leader & 59 & 339.624 \\
\hline Master bomb-maker technician & 23 & 294.187 \\
\hline Main military training instructor & 45 & 293.108 \\
\hline Courier for Noordin & 77 & 129.65 \\
\hline $\begin{array}{r}\text { Operative in the Marriot bombing, he gave to Noordin } \\
\text { the leftover explosive from the Chrismas eve bombing. } \\
\text { Robber }\end{array}$ & 72 & 103.599 \\
\hline Instructor, with planning and logistic expertise & 61 & 101.373 \\
\hline $\begin{array}{r}\text { Suicide bomber candidate in the Australian embassy } \\
\text { bombing }\end{array}$ & 37 & 77.076 \\
\hline Jl well-known bomber, leader of a small local team & 33 & 75.03 \\
\hline explosive transporter & 51 & 74.916 \\
\hline University teacher, expert in training & 8 & 74.041 \\
\hline $\begin{array}{r}23 \text { 's student, helped assemble Australian embassy } \\
\text { bombing }\end{array}$ & 38 & 66.422 \\
\hline Leader of Kompak organisation & 4 & 61.151 \\
\hline Preacher for the Darussalam Foundation & 70 & 58.847 \\
\hline $\begin{array}{r}\text { Helped } 45 \text { in a military training, member of the Darul } \\
\text { Islam }\end{array}$ & 66 & 49.241 \\
\hline
\end{tabular}




\begin{tabular}{|c|c|c|}
\hline & 53 & 47.676 \\
\hline & 13 & 47.589 \\
\hline & 19 & 47.269 \\
\hline & 73 & 47.173 \\
\hline & 74 & 47.14 \\
\hline & 43 & 46.165 \\
\hline & 68 & 44.042 \\
\hline Robber for Noordin & 2 & 43.205 \\
\hline \multirow[t]{4}{*}{ Well-known bomber in Bali I } & 40 & 42.87 \\
\hline & 60 & 40.613 \\
\hline & 21 & 38.405 \\
\hline & 46 & 29.407 \\
\hline $\begin{array}{r}\text { Operative in the Marriott bombing, helped to hide } \\
\text { Noordin and as personal chauffeur }\end{array}$ & 44 & 29.017 \\
\hline \multirow{5}{*}{$\begin{array}{r}\text { Secretary of the central command for Marriot bombing. } \\
\text { Teacher at Luqmanul Hakiem school }\end{array}$} & 7 & 25.06 \\
\hline & 26 & 24.101 \\
\hline & 24 & 22.08 \\
\hline & 35 & 19.534 \\
\hline & 10 & 18.772 \\
\hline $\begin{array}{r}\text { Bali I bomber, helped to provide weapons, Afghan } \\
\text { alumno with extensive experience }\end{array}$ & 75 & 16.442 \\
\hline
\end{tabular}




\begin{tabular}{|c|c|c|}
\hline Darum Islam trainee & 65 & 16.34 \\
\hline explosive provider & 34 & 16.291 \\
\hline \multirow[t]{17}{*}{$\begin{array}{r}\text { Well-known Bali bomber I, Afghan alumno with } \\
\text { extensive experience }\end{array}$} & 28 & 16.29 \\
\hline & 36 & 16.143 \\
\hline & 29 & 16.046 \\
\hline & 78 & 12.99 \\
\hline & 50 & 9.248 \\
\hline & 69 & 7 \\
\hline & 18 & 3.5 \\
\hline & 64 & 3.5 \\
\hline & 16 & 0.5 \\
\hline & 1 & 0 \\
\hline & 3 & 0 \\
\hline & 5 & 0 \\
\hline & 6 & 0 \\
\hline & 9 & 0 \\
\hline & 11 & 0 \\
\hline & 12 & 0 \\
\hline & 14 & 0 \\
\hline
\end{tabular}




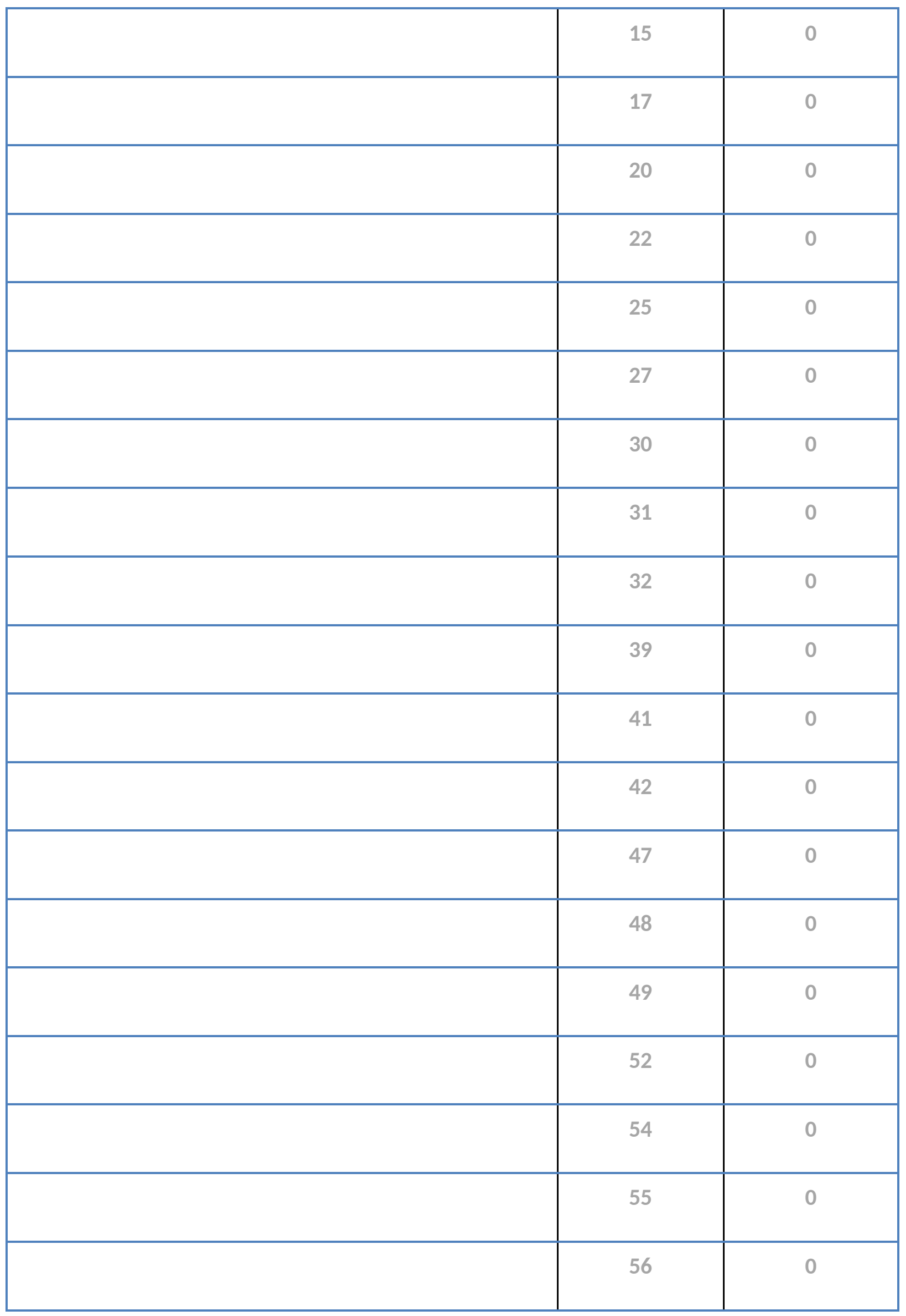




\begin{tabular}{|c|c|c|}
\hline & 57 & 0 \\
\hline & 58 & 0 \\
\hline & 62 & 0 \\
\hline & 63 & 0 \\
\hline & 67 & 0 \\
\hline & 71 & 0 \\
\hline
\end{tabular}


Table 6. The ranking of individuals for knowledge received.

\begin{tabular}{|c|c|c|}
\hline Role & ID & $\begin{array}{l}\text { Knowledge } \\
\text { Received }\end{array}$ \\
\hline Suicide bomber candidate in Bali bombing II & 64 & 103.515 \\
\hline $\begin{array}{r}\text { Trainee and trainer of suicide bombers for Bali } \\
\text { bombing II }\end{array}$ & 18 & 103.457 \\
\hline Suicide bomber candidate in Bali bombing II & 50 & 103.142 \\
\hline $\begin{array}{r}\text { Provided religious instructions and support to martyrs, } \\
\text { operative in the Australian embassy bombing }\end{array}$ & 24 & 102.561 \\
\hline 23's bomb-maker student and recruiter & 46 & 101.654 \\
\hline \multirow[t]{3}{*}{ Courier for Noordin } & 69 & 100.999 \\
\hline & 23 & 94.043 \\
\hline & 59 & 90.089 \\
\hline Courier for Noordin & 13 & 88.427 \\
\hline $\begin{array}{r}\text { Broker between Noordin and Abdullah Sunata, leader } \\
\text { of Kompak }\end{array}$ & 60 & 87.854 \\
\hline Helped to hide Noordin & 47 & 80.04 \\
\hline $\begin{array}{r}\text { KOMPAK member, helped in organising the Sunata- } \\
\text { Noordin meeting }\end{array}$ & 53 & 74.278 \\
\hline 23's bomb-maker student for Bali bombing II & 26 & 71.504 \\
\hline Helped to hide Noordin and 23 & 39 & 70.105 \\
\hline \multirow[t]{2}{*}{$\begin{array}{r}\text { Helped to hide Noordin, also worked as recruiter for } \\
\text { the Australian embassy bombing }\end{array}$} & 35 & 68.761 \\
\hline & 45 & 67.206 \\
\hline
\end{tabular}




\begin{tabular}{|c|c|c|}
\hline $\begin{array}{l}\text { Operative in the Australian embassy bombing. } \\
\text { Recruited by } 45 \text {. Also, helped to hide Noordin }\end{array}$ & 12 & 63.152 \\
\hline $\begin{array}{l}\text { Involved in moving the detonating cord used in the } \\
\text { Australian embassy bombing }\end{array}$ & 42 & 63.152 \\
\hline $\begin{array}{r}\text { Recruited as possible suicide bomber for the Marriott } \\
\text { bombing, also helped to hide Noordin }\end{array}$ & 25 & 63.132 \\
\hline $\begin{array}{l}\text { Operative in the Australian embassy bombing. } \\
\text { Recruited by } 45 \text {. Also helped to hide Noordin }\end{array}$ & 10 & 62.999 \\
\hline Courier for Noordin & 73 & 62.088 \\
\hline $\begin{array}{r}\text { Suicide bomber candidate in Australian embassy } \\
\text { bombing }\end{array}$ & 19 & 62.065 \\
\hline Darul Islam member, and military veteran & 74 & 62.056 \\
\hline \multirow[t]{2}{*}{ Helped to hide Noordin and 23} & 68 & 62.039 \\
\hline & 38 & 61.919 \\
\hline \multirow[t]{4}{*}{45 's student } & 43 & 61.82 \\
\hline & 8 & 61.192 \\
\hline & 37 & 61.037 \\
\hline & 77 & 59.951 \\
\hline \multirow[t]{2}{*}{ Head of Kompak office from 2004 in a local area } & 21 & 43.444 \\
\hline & 66 & 39.901 \\
\hline \multirow[t]{3}{*}{ Darul Islam leader } & 16 & 38.889 \\
\hline & 70 & 31.107 \\
\hline & 4 & 17.67 \\
\hline
\end{tabular}




\begin{tabular}{|c|c|c|}
\hline Leader of a local commander in Kayamanya & 36 & 17.435 \\
\hline $\begin{array}{r}\text { Member of the Abu Bakar Battalion, arranged a } \\
\text { training in Mindanao }\end{array}$ & 29 & 17.421 \\
\hline \multirow[t]{4}{*}{$\begin{array}{r}\text { Head of Jl's east Java office, helped to protect Noordin } \\
\text { after Marriott bombing }\end{array}$} & 78 & 13.93 \\
\hline & 7 & 13.019 \\
\hline & 61 & 11.219 \\
\hline & 44 & 10.968 \\
\hline Helped at early stages of Marriott bombing & 52 & 10.909 \\
\hline $\begin{array}{r}\text { Helped for the Marriott bombing by renting a house } \\
\text { for Noordin, buying the vehicles and moving } \\
\text { explosives }\end{array}$ & 71 & 10.898 \\
\hline $\begin{array}{r}\text { JI member, helped to store the explosive and opened } \\
\text { a bank account for Noordin }\end{array}$ & 67 & 10.872 \\
\hline \multirow[t]{4}{*}{ Suicide bomber candidate for Marriott bombing } & 22 & 10.869 \\
\hline & 51 & 9.923 \\
\hline & 33 & 9.908 \\
\hline & 72 & 9.418 \\
\hline \multirow[t]{3}{*}{$\begin{array}{r}\text { Head of Mantiqi I, became a member of the Jl central } \\
\text { command }\end{array}$} & 11 & 7.48 \\
\hline & 28 & 7.009 \\
\hline & 75 & 7.009 \\
\hline \multirow[t]{2}{*}{ Operative for the Atrium Mall bombing on 2001} & 49 & 6.396 \\
\hline & 34 & 5.878 \\
\hline
\end{tabular}




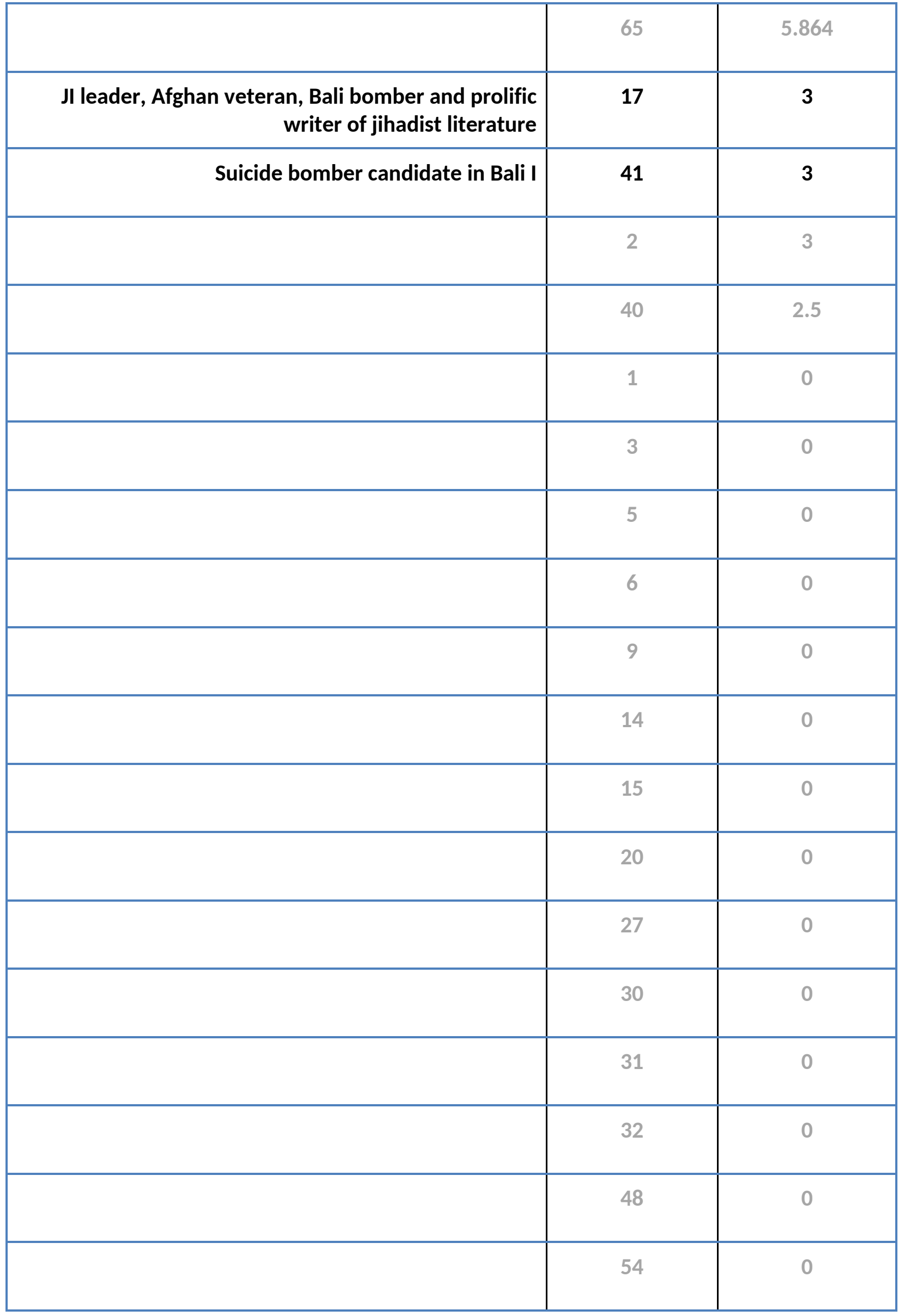




\begin{tabular}{|c|c|c|}
\hline & 55 & 0 \\
\hline & 56 & 0 \\
\hline & 57 & 0 \\
\hline & 58 & 0 \\
\hline & 62 & 0 \\
\hline & 63 & 0 \\
\hline
\end{tabular}

